\title{
Writing PET into existence
}

\author{
A. Chiti • M. Kirienko • E. Incerti • M. Picchio
}

Received: 2 September 2013 / Accepted: 3 September 2013 /Published online: 27 September 2013

(C) Springer-Verlag Berlin Heidelberg 2013

In this issue of the EJNMMI, a study evaluating a promising new PET tracer for imaging prostate cancer (PCa), ${ }^{68} \mathrm{Ga}-$ PSMA (PSMA), is published [1]. The paper deals with a retrospective analysis in 37 patients with biochemical recurrence of $\mathrm{PCa}$ who underwent both ${ }^{18} \mathrm{~F}$-fluoromethylcholine (CHO) and PSMA PET/CT for the purpose of restaging. The aim of the study was to compare the diagnostic performance of the novel tracer with that of CHO. On a patient basis, the detection rates were $70.3 \%$ and $86.5 \%$ for CHO and PSMA, respectively. PSMA also showed a better performance at low PSA values. The authors conclude that PSMA PET/CT can detect $\mathrm{PCa}$ relapse and metastasis with significantly improved contrast when compared with CHO PET/CT. This advantage is related to higher tracer uptake by PCa lesions and low background signal, which allow the detection of small lymph node, bone and liver metastases. Although innovative and interesting, this study had some limitations: it was retrospective; few lesions were confirmed by histology; several criteria were used to validate the uptake areas; the results were compared against $\mathrm{CHO} \mathrm{PET} / \mathrm{CT}$, which was considered as a standard even though this modality is not established; and, finally, the impact on patient management is not discussed.

The limitations of the study preclude recommendation of this new radiopharmaceutical in oncological guidelines, a fate

\footnotetext{
A. Chiti $(\bowtie)$

Nuclear Medicine, Humanitas Research Institute, Milan, Italy

e-mail: arturo.chiti@humanitas.it

M. Kirienko

University Milano-Bicocca, Milan, Italy

E. Incerti $\cdot$ M. Picchio

Nuclear Medicine Unit, Scientific Institute San Raffaele, Milan, Italy

M. Picchio

Institute for Bio-Imaging and Molecular Physiology, National

Research Council (IBFM-CNR), Segrate, Milan, Italy
}

that has befallen many other promising PET tracers. This is a critical issue for the future of nuclear medicine and deserves a commentary. The way we introduce new radiopharmaceuticals into the clinical arena is highly influenced by published data and we believe that efforts are needed to enhance the impact of our reports in the world of oncology.

Although many readers are well aware of PCa imaging, let us briefly summarize the state of the art of PET radiopharmaceuticals that are used to study PCa.

$\mathrm{PCa}$ is a considerable health issue and has displayed an increasing incidence worldwide during the last decade [2] - a trend that justifies the burgeoning medical interest in this disease. We can say that PCa is studied as much in men as breast cancer is studied in, mostly, women. As always in oncology, accurate detection of disease spread is crucial for treatment decisions and imaging could play a major role in identifying tumour extension, provided that sufficient diagnostic accuracy is properly demonstrated. Of course, PET imaging is competing on many levels with other diagnostic modalities, but we will not cover these aspects. As a consequence of the great clinical interest in PCa, several PET radiopharmaceuticals have been investigated for their ability to detect the disease [3]. The role of the "pan-tumour" radiopharmaceutical FDG is limited, mainly due to its low sensitivity, particularly in patients with a low Gleason score, low serum PSA values and localized disease [4]. However, it has been suggested that FDG may be useful when applied in specific clinical settings, such as in staging high-risk patients, in the assessment of the spread of hormone-resistant disease, in the evaluation of treatment response, and in the assessment of prognosis in patients with metastatic PCa [5]. Nevertheless, the limited availability of evidence means that it is difficult to go beyond the hypothesis of a possible utility of FDG in aggressive disease.

Among the different PET tracers proposed for PCa, choline derivatives are the most commonly used, especially in patients with biochemical failure [6]. Acetate and $\mathrm{CHO}$ have 
comparable accuracy in visualizing PCa, but most of the recent studies have focused on $\mathrm{CHO}$ [7]. Practical issues led to the development of fluorinated compounds, such as ${ }^{18} \mathrm{~F}$ fluoroethylcholine and $\mathrm{CHO}$, to overcome the limitations of ${ }^{11} \mathrm{C}$-labelled radiopharmaceuticals. These various $\mathrm{CHO}$-based tracers have shown some differences in their biokinetics [8], and it is not yet established which radiopharmaceutical is more accurate because there have been no direct comparative studies on individual compounds. However, no significant differences have been observed in the clinical setting, and running such a comparative study would not be of any clinical value. Although not validated by prospective, randomized clinical trials, $\mathrm{CHO}$ is increasingly being used for imaging of primary and recurrent $\mathrm{PCa}$ [9]. For the diagnosis of primary $\mathrm{PCa}, \mathrm{CHO}$ has shown controversial results due to the heterogeneity of the patient groups included in the published experience [10]. Choline has demonstrated low sensitivity for the detection of primary prostate lesions and tumour configuration has been shown to affect diagnostic accuracy. Additionally, specificity is limited because $\mathrm{PCa}$ cannot be distinguished from prostatic hyperplasia, prostatitis and high-grade intraepithelial neoplasia [11]. For these reasons, the use of $\mathrm{CHO}$ cannot be recommended as a procedure for PCa detection. At least, however, we know when not to use this technique.

In staging, it is usually stated that the use of $\mathrm{CHO}$ should be restricted to patients with high-risk disease. Clinical factors, high Gleason scores $(>8)$ and high PSA levels $(>20 \mathrm{ng} / \mathrm{ml})$, should be considered in patient selection in order to ensure that there is some benefit from the use of this procedure [12]. Nevertheless, data are also lacking on this possible application.

In cases of biochemical failure after primary treatment, the accuracy of $\mathrm{CHO}$ in localizing recurrent disease has been extensively reported, but mainly in retrospective studies [6, 13]. The higher the PSA level and the shorter the PSA doubling time, the better will be the predictive value of this imaging modality [14]. Indeed, when the PSA level is $>1 \mathrm{ng} / \mathrm{ml}$, CHO has better accuracy than standard diagnostic procedures [15], and a PSA doubling time of less than 3 months to a maximum of 6 months has been suggested to be predictive of CHO positivity [16-18]. It is well known that the choice of treatment depends on disease spread [19], and $\mathrm{CHO}$ has been used to guide surgical and radiation treatments [20-22]. In particular, it has been postulated that CHO is useful in salvage radiation treatment planning as it allows accurate definition of radiation field extension and guidance of dose escalation to positive areas [23]. When validated, this may offer a brilliant example of personalized medicine, not to mention the use of negative $\mathrm{CHO}$ results to propose a "watchful waiting" approach to patients.

Based on the available knowledge, there is insufficient evidence to support the withdrawal of antiandrogen therapy on a regular basis before $\mathrm{CHO}$ imaging in patients with hormone-resistant $\mathrm{PCa}[24,25]$. Again, we at least know what we should not do.

An apparently promising radiopharmaceutical is ${ }^{18} \mathrm{~F}$-labelled anti-1-amino-3- ${ }^{18}$ F-fluorocyclobutane-1-carboxylic acid (FACBC), a new synthetic amino acid that was developed for assessment of the anabolic component of tumour metabolism. FACBC shows high uptake in PCa deposits and appears to be safe for use in humans [26]. Preliminary data have shown that it might be superior to ${ }^{11} \mathrm{C}-\mathrm{CHO}$ in the detection of recurrent $\mathrm{PCa}$, but to date the only available report is that of a study in a small series of patients in which the results did not reach statistical significance and two nonestablished diagnostic modalities were compared, with no histological confirmation of the uptake areas [27].

The second "new" radiopharmaceutical, reported in this issue of the EJNMMI, is PSMA. The molecule is a type II transmembrane protein with glutamate-carboxypeptidase activity that is overexpressed in PCa [28, 29]. PSMA expression levels seem to be directly related to androgen independence, metastasis and progression of the tumour [30], and this is why it has been widely investigated for the development of several radiopharmaceuticals, for both PET and SPECT [31-36]. The ${ }^{68} \mathrm{Ga}$-labelled PSMA ligand has been previously investigated, with studies suggesting a better sensitivity compared with CHO [37, 38].

A major problem commonly encountered in clinical studies employing new diagnostic modalities, such as PET/CT radiopharmaceuticals, lies in the difficulty of assessing the accuracy of the technique. Histological verification of findings is often not possible for practical and ethical reasons. One of the best, or worst, examples of this critical situation is the use of choline in PCa. The clinical setting in which this radiopharmaceutical could be more useful is precisely that in which the validation process for any finding is particularly difficult. This is why, although many papers have been published reporting clinical studies using $\mathrm{CHO}$ and many centres throughout Europe are using this technique in clinical routine, $\mathrm{CHO}$ is still considered experimental and is not recommended in guidelines [39-41]. In fact, comparative studies of $\mathrm{CHO}$ with standard approach methodologies, which are recommended in clinical guidelines, are scarce, and randomized controlled trials evaluating the impact of $\mathrm{CHO}$ on patient management and outcome have still not been published. This situation is in a way a paradox. In fact, since imaging is almost neglected in all clinical guidelines on $\mathrm{PCa}$, it would be easy to demonstrate with a properly designed and conducted clinical trial the superiority of $\mathrm{CHO}$, or any other radiopharmaceutical, over CT or bone scan, for both staging and biochemical relapse.

We are of the opinion that a strong behavioural change is needed in the attitude of the nuclear medicine community towards imaging validation.

The good old days when everyone was allowed to use every tracer (of course having demonstrated fulfilment of the 
radiation protection requirements) are definitively over. Now we have to compete with several other diagnostic modalities, most of which do not use ionizing radiation and are cheaper and less complicated. So, we have to demonstrate that PET radiopharmaceuticals are beneficial for our patients and that the community has sufficient reason to pay for their use. The level of evidence that is needed to accept a diagnostic modality is a matter of debate, and here we have to enter the scientific and political arena and fight to obtain a different, and easier, way to gain acceptance of a diagnostic modality in clinical guidelines. We should immediately start this effort in simple ways, keeping in mind that readily available, easy-touse and approved radiopharmaceuticals are the only way to ensure that nuclear medicine "stands clear" in the clinical world. Let us just start by designing proper studies aimed at demonstrating, not at postulating. Let us gather data from different centres, with significant numbers of patients, and let us delay publication until we have data on outcome or on surrogate markers of outcome.

We have to publish our results in order that the full value of radiopharmaceuticals is recognized within the oncology community, with the proviso that we are able to demonstrate this value. In other words, we should aim to make full use of PET's potential in clinical practice, but we should also write papers and publish results in the proper way. That is to say: writing PET into existence.

\section{References}

1. Ali Afshar-Oromieh CMZ, Anna Malcher, Matthias Eder, Michael, Eisenhut HGL, T. Holland-Letz, et al. Comparison of PET imaging with a $68 \mathrm{Ga}$-labelled PSMA-ligand and 18F-choline based PET/CT for the diagnosis of recurrent prostate cancer. Eur J Nucl Med Mol Imaging. 2013. doi:10.1007/s00259-013-2525-5.

2. Jemal A, Siegel R, Xu J, Ward E. Cancer statistics, 2010. CA Cancer J Clin. 2010;60:277-300. doi:10.3322/caac.20073.

3. Fox JJ, Schoder H, Larson SM. Molecular imaging of prostate cancer. Curr Opin Urol. 2012;22:320-7. doi:10.1097/MOU. 0b013e32835483d5.

4. Jadvar H. Molecular imaging of prostate cancer: PET radiotracers. AJR Am J Roentgenol. 2012;199:278-91. doi:10.2214/AJR.12. 8816.

5. Jadvar H. Imaging evaluation of prostate cancer with (18)Ffluorodeoxyglucose PET/CT: utility and limitations. Eur J Nucl Med Mol Imaging. 2013;40 Suppl 1:5-10. doi:10.1007/s00259013-2361-7.

6. Evangelista L, Zattoni F, Guttilla A, Saladini G, Colletti PM, Rubello D. Choline PET or PET/CT and biochemical relapse of prostate cancer: a systematic review and meta-analysis. Clin Nucl Med. 2013;38:305-14. doi:10.1097/RLU.0b013e3182867f3c.

7. Brogsitter C, Zophel K, Kotzerke J. (18)F-Choline, (11)C-choline and $(11) \mathrm{C}$-acetate PET/CT: comparative analysis for imaging prostate cancer patients. Eur J Nucl Med Mol Imaging. 2013;40 Suppl 1: 18-27. doi:10.1007/s00259-013-2358-2.

8. DeGrado TR, Baldwin SW, Wang S, Orr MD, Liao RP, Friedman HS, et al. Synthesis and evaluation of (18)F-labeled choline analogs as oncologic PET tracers. J Nucl Med. 2001;42:1805-14.
9. Krause BJ, Souvatzoglou M, Treiber U. Imaging of prostate cancer with PET/CT and radioactively labeled choline derivates. Urol Oncol. 2013;31:427-35. doi:10.1016/j.urolonc.2010.08.008.

10. Umbehr MH, Muntener M, Hany T, Sulser T, Bachmann LM. The role of $11 \mathrm{C}$-choline and $18 \mathrm{~F}$-fluorocholine positron emission tomography (PET) and PET/CT in prostate cancer: a systematic review and meta-analysis. Eur Urol. 2013;64:106-17. doi:10.1016/j.eururo. 2013.04.019.

11. Souvatzoglou M, Weirich G, Schwarzenboeck S, Maurer T, Schuster T, Bundschuh RA, et al. The sensitivity of [11C]choline PET/CT to localize prostate cancer depends on the tumor configuration. Clin Cancer Res. 2011;17:3751-9. doi:10.1158/1078-0432.CCR-102093.

12. Beheshti M, Haim S, Zakavi R, Steinmair M, Waldenberger P, Kunit $\mathrm{T}$, et al. Impact of $18 \mathrm{~F}$-choline PET/CT in prostate cancer patients with biochemical recurrence: influence of androgen deprivation therapy and correlation with PSA kinetics. J Nucl Med. 2013;54:833-40. doi:10.2967/jnumed.112.110148.

13. Beer AJ, Eiber M, Souvatzoglou M, Schwaiger M, Krause BJ. Radionuclide and hybrid imaging of recurrent prostate cancer. Lancet Oncol. 2011;12:181-91. doi:10.1016/S1470-2045(10)70103-0.

14. Castellucci P, Picchio M. (11)C-Choline PET/CT and PSA kinetics. Eur J Nucl Med Mol Imaging. 2013;40 Suppl 1:36-40. doi:10.1007/ s00259-013-2377-z.

15. Picchio M, Briganti A, Fanti S, Heidenreich A, Krause BJ, Messa C, et al. The role of choline positron emission tomography/computed tomography in the management of patients with prostate-specific antigen progression after radical treatment of prostate cancer. Eur Urol. 2011;59:51-60. doi:10.1016/j.eururo.2010.09.004.

16. Castellucci P, Fuccio C, Rubello D, Schiavina R, Santi I, Nanni C, et al. Is there a role for (1)(1)C-choline PET/CT in the early detection of metastatic disease in surgically treated prostate cancer patients with a mild PSA increase $<1.5 \mathrm{ng} / \mathrm{ml}$ ? Eur J Nucl Med Mol Imaging. 2011;38:55-63. doi:10.1007/s00259-010-1604-0.

17. Giovacchini G, Picchio M, Garcia-Parra R, Mapelli P, Briganti A, Montorsi $\mathrm{F}$, et al. [11C]choline positron emission tomography/ computerized tomography for early detection of prostate cancer recurrence in patients with low increasing prostate specific antigen. J Urol. 2013;189:105-10. doi:10.1016/j.juro.2012.09.001.

18. Giovacchini G, Picchio M, Coradeschi E, Bettinardi V, Gianolli L, Scattoni V, et al. Predictive factors of $[(11) \mathrm{C}]$ choline PET/CT in patients with biochemical failure after radical prostatectomy. Eur J Nucl Med Mol Imaging. 2010;37:301-9. doi:10.1007/s00259-0091253-3.

19. Soyka JD, Muster MA, Schmid DT, Seifert B, Schick U, Miralbell R, et al. Clinical impact of $18 \mathrm{~F}$-choline PET/CT in patients with recurrent prostate cancer. Eur J Nucl Med Mol Imaging. 2012;39:936-43. doi:10.1007/s00259-012-2083-2.

20. Picchio M, Giovannini E, Crivellaro C, Gianolli L, di Muzio N, Messa C. Clinical evidence on PET/CT for radiation therapy planning in prostate cancer. Radiother Oncol. 2010;96:347-50. doi:10. 1016/j.radonc.2010.07.016.

21. Passoni NM, Di Trapani E, Suardi N, Gallina A, Abdollah F, Bianchi $\mathrm{M}$, et al. Clinical and diagnostic assessment for therapeutic decisions in prostate cancer. Q J Nucl Med Mol Imaging. 2012;56:321-30.

22. Rigatti P, Suardi N, Briganti A, Da Pozzo LF, Tutolo M, Villa L, et al. Pelvic/retroperitoneal salvage lymph node dissection for patients treated with radical prostatectomy with biochemical recurrence and nodal recurrence detected by $[11 \mathrm{C}]$ choline positron emission tomography/computed tomography. Eur Urol. 2011;60:935-43. doi: 10.1016/j.eururo.2011.07.060.

23. Schwarzenbock SM, Kurth J, Gocke C, Kuhnt T, Hildebrandt G, Krause BJ. Role of choline PET/CT in guiding target volume delineation for irradiation of prostate cancer. Eur J Nucl Med Mol Imaging. 2013;40 Suppl 1:28-35. doi:10.1007/s00259-013-2404-0. 
24. Giovacchini G, Picchio M, Scattoni V, Garcia Parra R, Briganti A, Gianolli $\mathrm{L}$, et al. PSA doubling time for prediction of [(11)C]choline $\mathrm{PET} / \mathrm{CT}$ findings in prostate cancer patients with biochemical failure after radical prostatectomy. Eur J Nucl Med Mol Imaging. 2010;37: 1106-16. doi:10.1007/s00259-010-1403-7.

25. Dost RJ, Glaudemans AW, Breeuwsma AJ, de Jong IJ. Influence of androgen deprivation therapy on choline PET/CT in recurrent prostate cancer. Eur J Nucl Med Mol Imaging. 2013;40 Suppl 1:41-7. doi:10.1007/s00259-013-2398-7.

26. Schuster DM, Taleghani PA, Nieh PT, Master VA, Amzat R, SavirBaruch B, et al. Characterization of primary prostate carcinoma by anti1-amino-2-[(18)F] -fluorocyclobutane-1-carboxylic acid (anti-3[(18)F] FACBC) uptake. Am J Nucl Med Mol Imaging. 2013;3:85-96.

27. Nanni C, Schiavina R, Boschi S, Ambrosini V, Pettinato C, Brunocilla E, et al. Comparison of (18)F-FACBC and (11)C-choline $\mathrm{PET} / \mathrm{CT}$ in patients with radically treated prostate cancer and biochemical relapse: preliminary results. Eur J Nucl Med Mol Imaging. 2013;40 Suppl 1:11-7. doi:10.1007/s00259-013-2373-3.

28. Silver DA, Pellicer I, Fair WR, Heston WD, Cordon-Cardo C. Prostate-specific membrane antigen expression in normal and malignant human tissues. Clin Cancer Res. 1997;3:81-5.

29. Perner S, Hofer MD, Kim R, Shah RB, Li H, Moller P, et al. Prostatespecific membrane antigen expression as a predictor of prostate cancer progression. Hum Pathol. 2007;38:696-701. doi:10.1016/j. humpath.2006.11.012.

30. Mannweiler S, Amersdorfer P, Trajanoski S, Terrett JA, King D, Mehes G. Heterogeneity of prostate-specific membrane antigen (PSMA) expression in prostate carcinoma with distant metastasis. Pathol Oncol Res. 2009;15:167-72. doi:10.1007/s12253-008-9104-2.

31. Osborne JR, Akhtar NH, Vallabhajosula S, Anand A, Deh K, Tagawa ST. Prostate-specific membrane antigen-based imaging. Urol Oncol. 2013;31:144-54. doi:10.1016/j.urolonc.2012.04.016.

32. Hillier SM, Maresca KP, Femia FJ, Marquis JC, Foss CA, Nguyen N, et al. Preclinical evaluation of novel glutamate-urea-lysine analogues that target prostate-specific membrane antigen as molecular imaging pharmaceuticals for prostate cancer. Cancer Res. 2009;69:6932-40. doi:10.1158/0008-5472.CAN-09-1682.
33. Eder M, Eisenhut M, Babich J, Haberkorn U. PSMA as a target for radiolabelled small molecules. Eur J Nucl Med Mol Imaging. 2013;40:819-23. doi:10.1007/s00259-013-2374-2.

34. Chen Y, Pullambhatla M, Foss CA, Byun Y, Nimmagadda S, Senthamizhchelvan S, et al. 2-(3-\{1-Carboxy-5-[(6-[18F]fluoro-pyridine-3-carbonyl)-amino]-pentyl $\}$-ureido)-pen tanedioic acid, [18F]DCFPyL, a PSMA-based PET imaging agent for prostate cancer. Clin Cancer Res. 2011;17:7645-53. doi:10.1158/1078-0432. CCR-11-1357.

35. Maresca KP, Hillier SM, Femia FJ, Keith D, Barone C, Joyal JL, et al. A series of halogenated heterodimeric inhibitors of prostate specific membrane antigen (PSMA) as radiolabeled probes for targeting prostate cancer. J Med Chem. 2009;52:347-57. doi:10.1021/jm800994j.

36. Mease RC, Foss CA, Pomper MG. PET imaging in prostate cancer: focus on prostate-specific membrane antigen. Curr Top Med Chem. 2013;13:951-62.

37. Afshar-Oromieh A, Haberkorn U, Eder M, Eisenhut M, Zechmann CM. [68Ga]Gallium-labelled PSMA ligand as superior PET tracer for the diagnosis of prostate cancer: comparison with 18F-FECH. Eur J Nucl Med Mol Imaging. 2012;39:1085-6. doi:10.1007/s00259012-2069-0.

38. Afshar-Oromieh A, Malcher A, Eder M, Eisenhut M, Linhart HG, Hadaschik BA, et al. PET imaging with a [68Ga]gallium-labelled PSMA ligand for the diagnosis of prostate cancer: biodistribution in humans and first evaluation of tumour lesions. Eur J Nucl Med Mol Imaging. 2013;40:486-95. doi:10.1007/s00259-012-2298-2.

39. Heidenreich A, Bellmunt J, Bolla M, Joniau S, Mason M, Matveev V, et al. EAU guidelines on prostate cancer. Part 1: screening, diagnosis, and treatment of clinically localised disease. Eur Urol. 2011;59:61-71.

40. Casalino DD, Remer EM, Arellano RS, Bishoff JT, Coursey CA, Dighe $\mathrm{M}$, et al. ACR Appropriateness Criteria(R) posttreatment follow-up of prostate cancer. J Am Coll Radiol. 2011;8:863-71. doi:10.1016/j.jacr.2011.09.003.

41. Mottet N, Bellmunt J, Bolla M, Joniau S, Mason M, Matveev V, et al. EAU guidelines on prostate cancer. Part II: Treatment of advanced, relapsing, and castration-resistant prostate cancer. Eur Urol. 2011;59: $572-83$. 